\title{
Weight Goals, Disordered Eating Behaviors, and BMI Trajectories in US Young Adults
}

\author{
Jonathan Chu, BA' ${ }^{7}$, Kyle T. Ganson, $P h D, M S W^{2}$, Eric Vittinghoff, $P h D^{3}$, \\ Deborah Mitchison, MClinPsych, PhD ${ }^{4,5}$, Phillipa Hay, DPhil, MD ${ }^{4,6}$, \\ Jennifer Tabler, PhD, MS $S^{7}$, Rachel F. Rodgers, PhD ${ }^{8,9}$, Stuart B. Murray, DClinPsych, PhD ${ }^{10}$, \\ and Jason M. Nagata, MD, MSc ${ }^{7}$ (D) \\ 'Division of Adolescent and Young Adult Medicine, Department of Pediatrics, University of California, San Francisco, San Francisco, CA, USA; \\ ${ }^{2}$ Factor-Inwentash Faculty of Social Work, University of Toronto, Toronto, ON, Canada; ${ }^{3}$ Department of Epidemiology and Biostatistics, University of \\ California, San Francisco, San Francisco, CA, USA; ${ }^{4}$ Translational Health Research Institute, School of Medicine, Western Sydney University, Penrith, \\ NSW, Australia; ${ }^{5}$ Department of Psychology, Macquarie University, Macquarie Park, NSW, Australia; ${ }^{6}$ Camden and Campbell Town Hospitals, \\ Campbelltown, NSW, Australia; ${ }^{7}$ Department of Criminal Justice and Sociology, University of Wyoming, Laramie, WY, USA; ${ }^{8}$ APPEAR, Department of \\ Applied Psychology, Northeastern University, Boston, MA, USA; ${ }^{9}$ Department of Psychiatric Emergency \& Acute Care, Lapeyronie Hospital, CHRU, \\ Montpellier, France; ${ }^{10}$ Department of Psychiatry and Behavioral Sciences, University of Southern California, Los Angeles, CA, USA.
}

BACKGROUND: Community sample data indicate that weight control efforts in young adulthood may have associations with greater increases in body mass index (BMI) over time.

OBJECTIVE: To determine the prospective associations between weight goals and behaviors in young adults and BMI trajectories over 15-year follow-up using a nationally representative sample.

DESIGN: Longitudinal cohort data collected from 2001 to 2018 of the National Longitudinal Study of Adolescent to Adult Health.

PARTICIPANTS: Young adults aged 18-26 years old at baseline stratified by gender and BMI category.

MAIN MEASURES: Predictors: weight goals, any weight loss/maintenance behaviors, dieting, exercise, disordered eating behaviors. Outcomes: BMI at 7- and 15-year follow-up.

KEY RESULTS: Of the 12,155 young adults in the sample (54\% female, 32\% non-White), 33.2\% reported a goal to lose weight, $15.7 \%$ to gain weight, and $14.6 \%$ to maintain weight. In unadjusted models, all groups have higher mean BMI at 7- and 15-year follow-up. In mixed effect models, goals to lose weight in men with $\mathrm{BMI}<18.5$ $\left(5.94 \mathrm{~kg} / \mathrm{m}^{2}\right.$; 95\% CI 2.58, 9.30) and goals to maintain weight in men with $\mathrm{BMI} \geq 25(0.44 ; 95 \% \mathrm{CI} 0.15,0.72)$ were associated with greater BMI increase compared to no weight goal. Engaging in disordered eating behaviors was associated with greater BMI increase in men with BMI < $18.5(5.91 ; 2.96,8.86)$ and women with $18.5 \leq \mathrm{BMI}<25$ $(0.40 ; 0.16,0.63)$. Dieting $(-0.24 ;-0.41,-0.06)$ and exercise $(-0.31 ;-0.45,-0.17)$ were associated with lower $\mathrm{BMI}$ increase in women with $18.5 \leq \mathrm{BMI}<25$. In women with $\mathrm{BMI}<18.5$, dieting was associated with greater BMI increase (1.35; 0.33, 2.37).

CONCLUSIONS: Weight control efforts may have variable effects on BMI over time by gender and BMI category. These findings underscore the need to counsel patients

Prior Presentations: None.

Received July 29, 2020

Accepted March 7, 2021

Published online April 19, 2021 on the effectiveness of weight control efforts and long-term weight management.

KEYWORDS: BMI; weight goals; disordered eating behaviors; young adult; weight trajectories.

J Gen Intern Med 36(9):2622-30

DOI: $10.1007 / \mathrm{s} 11606-021-06702-\mathrm{y}$

(C) The Author(s) 2021

\section{INTRODUCTION}

According to national estimates in the USA, $40 \%$ of younger adults aged 20-39 years have a weight status classified as obese with body mass index (BMI, $\left.\mathrm{kg} / \mathrm{m}^{2}\right) \geq 30 .{ }^{1}$ Higher weight status is associated with many biomedical, psychosocial, and economic consequences, and as such, prevention in young adults has become a public health priority. ${ }^{2}$ In order to prevent obesity and conform to established body ideals, young adults may engage in various weight control behaviors. ${ }^{3-5}$ Studies have shown that individuals with BMI $\geq 25$ report a higher prevalence of weight control behaviors. ${ }^{6-11}$ Of concern, disordered eating behaviors (DEBs), such as fasting/ skipping meals, vomiting, and taking laxatives or diuretics, have been shown to increase future health risks, including eating disorders, alcohol and tobacco use, and depression, and are unhelpful for weight management. ${ }^{12-14}$

Previous longitudinal studies have shown associations between dieting in adolescence and future weight gain, but results have been inconsistent across studies. ${ }^{15-19}$ Recent longitudinal studies in Minnesota found that adolescents and young adults engaging in DEBs had higher BMI at 5-, 10-, and 15-year follow-up. ${ }^{6,20,21}$ Though these findings provide important context for weight control behaviors in adolescents, the external validity of the study was limited due to the lack of nationally representative data. Prior studies using nationally representative data from the National Longitudinal Study of Adolescent to Adult Health (Add Health) have shown 
associations between DEBs and higher BMI in individuals with BMI $\geq 25$ at 7 -year follow-up. However, these studies did not investigate the role of weight control behaviors in those with BMI < 25 (i.e., adequate or underweight) and also do not examine efforts to maintain weight after a desired weight has been achieved. Further studies are needed to examine the influence of weight control behaviors on long-term health across BMI categories. Doing so will not only elucidate the cognitive and behavioral factors that predict unhealthy transitions between BMI categories but also help identify interventions for prevention. ${ }^{14}$

While most studies have focused on the associations between weight loss/maintenance efforts and BMI change, there is growing interest in how weight gain efforts may impact future health. Previous studies using nationally representative data have shown that weight gain attempts have high prevalence among adolescent boys. ${ }^{3}$ These findings may reflect societal trends in which the ideal male body has become larger and more muscular, such as those represented in action figures and fitness magazines. ${ }^{22}$ In addition, most weight gain attempts were in adolescent boys who were considered adequate weight, overweight, or obese by BMI measures, suggesting implications for weight gain behaviors leading to overweight/obesity and greater risk for future health complications. ${ }^{3,} 23-25$ Additionally, studies have shown that preadolescent Black girls who are underweight endorse higher rates of weight gain attempts than their White counterparts, which may also reflect desires to comply with cultural ideals. ${ }^{26,} 27$ However, research on goals to gain weight is severely limited, and thus, additional study is needed to better understand and utilize effective obesity intervention and prevention methods.

The present study aims to fill the gap in scientific knowledge on the longitudinal effects of weight goals and weight control behaviors, such as exercise, dieting, and disordered behaviors on BMI trajectories, in young adulthood. The objective of this study was to determine the association in a large national sample of young adults between weight goals, weight control behaviors, and BMI at 7- and 15-year follow-up.

\section{METHODS}

\section{Sample}

We analyzed longitudinal cohort data from the National Longitudinal Study of Adolescent to Adult Health (Add Health), a nationally representative study of adolescents followed into adulthood in the USA. The initial adolescent sample (1994 1995, 11-18 years old, Wave I) used systemic sampling methods and implicit stratification to ensure that the high schools $(n=80)$ and middle schools $(n=52)$ were representative of US schools with respect to country region, size, urbanicity, type, and ethnicity. Thus far, there have been five waves of data collection, coordinated by the Carolina Population Center. For this study, we used restricted-use data from Wave III (defined as baseline for this study), collected from
2001 to 2002 when subjects were 18-24 years old, Wave IV (defined as 7-year follow-up for this study), collected in 2008 when subjects were 24-32 years old, and Wave V (defined as 15-year follow-up for this study), collected from 2016 to 2018 when subjects were 32-42 years old. Additional details regarding the study design may be found elsewhere. ${ }^{28,} 29$

In this study, we included all young adults with weight goal data at baseline and excluded young adults who were lost to follow-up at 7-year follow-up ( $n=2034)$ or missing data for the outcomes and covariates listed below $(n=133)$. The University of North Carolina Institutional Review Board approved all Add Health study procedures, and the University of California, San Francisco Institutional Review Board deemed this specific project exempt.

\section{Procedures}

At baseline and 7-year follow-up, an interviewer traveled to the home of or to another suitable location for the research subject. Written informed consent was obtained from the subject. Interviews lasted approximately $90 \mathrm{~min}$. Following the interview, interviewers took physical measurements. At 15-year follow-up, participants were either asked to complete a web-based or paper and pencil questionnaire or given an inperson interview. Following the questionnaire, respondents were asked if they would agree to schedule and participate in a home exam administered by a field examiner to attain physical measurements.

\section{Measures}

Baseline Measures. Weight Goals. At baseline, participants were asked, "What are you currently doing about your weight?" Individuals who reported "trying to lose weight," "gain weight or bulk up," "or stay the same weight" were coded as having a weight loss goal, weight gain goal, or weight maintenance goal, respectively. Those who reported "not trying to do anything" about their weight were coded as having no weight goal.

Weight Loss/Maintenance Behaviors. At baseline, individuals who reported a weight loss/maintenance goal were further asked to describe whether or not they engaged in specific behaviors to lose/maintain weight during the past 7 days, which included (1) dieting, (2) exercising, (3) fasting/ skipping meals, (4) throwing up, (5) taking weight loss pills, (6) using laxatives, or (7) using diuretics in the past 7 days. An affirmative response to any of (1)-(7) was coded as engaging in weight loss/maintenance behaviors. Individuals who selfreported behaviors (3) to (7) were further coded as engaging in DEBs, and those who self-reported throwing up, laxative use, or diuretic use were coded as engaging in purging behaviors. Our measurement of DEBs mirrors previous studies using Add Health data. ${ }^{8,9}$, 14, 30, 31 These questions were adapted from validated eating behavior measures, such as in the Adolescent Health Survey. They were similar to Project Eating 
Among Teens ( $85 \%$ agreement $\geq 1$ behavior, $r=0.76$ ) except that the time frame was 7 days to be consistent with the 7-day time frame of other validated questions in the Add Health survey on physical activity and nutrition. ${ }^{32-34}$

\begin{abstract}
Measured at Both Baseline and 7-Year Follow-up. Body mass index (BMI) was calculated using the standard formula weight $(\mathrm{kg})$ divided by height $(\mathrm{m})$ squared $(\mathrm{BMI}=$ weight/ height ${ }^{2}$ ). Weight and height were measured by the interviewer. If not measured by the interviewer, self-reported height or weight was used to calculate BMI. At Waves III, IV, and V, $95.3 \%, 85.3 \%$, and $43.2 \%$ of participants had objective height and weight measurements respectively.
\end{abstract}

Covariates. Age and sex were based on self-report.

Household income was based on self-reported parent's income at Wave I (1994-1995, ages 11-18) based on the question "how much income did you receive from personal earnings before taxes, that is, wages or salaries, including tips, bonuses, and overtime pay, and income from self-employment?" Gaussian normal regression imputation models were used to impute income for the 1638 parents who either refused to answer the income question or stated they did not know, similar to the method used in previous studies. ${ }^{35,36}$

Race/ethnicity was based on self-report, based on the categories suggested by the Add Health survey design: nonHispanic White, non-Hispanic Black/African American, Hispanic/Latino, non-Hispanic Asian or Pacific Islander, American Indian/Native American, or other.

\section{Statistical Analysis}

Data analysis was performed in 2020 using STATA 15.1. All baseline measures were calculated with weighted data to reflect the representative proportion in the target US population. We charted unadjusted BMI trajectories by weight goal using mean BMI at each wave. We used mixed effect models to assess prospective associations between weight goals and BMI at 7- and 15-year follow-up, using "no weight goal" as the reference group, adjusting for age, household income, race/ethnicity, and the interaction between wave and weight goal, and accounting for sample weighting. Mixed effect models were also used to evaluate the associations between BMI at 7- and 15-year follow-up as the continuous dependent variable and specific (1) weight loss/maintenance behaviors or (2) weight gain behaviors as the independent variable, adjusting for age, household income, race/ethnicity, and the interaction between wave and behavior and accounting for sample weighting. Given previously reported differences in prevalence and health associations of weight goals and behaviors by sex and BMI, outcomes were stratified by $\mathrm{BMI}<18.5,18.5$ $\leq \mathrm{BMI}<25$, or $\mathrm{BMI} \geq 25$ and sex. ${ }^{3,8,9}$ In sensitivity analyses, all findings were unchanged when further adjusted for baseline BMI. The Benjamini-Hochberg procedure was used to adjust for a false discovery rate given multiple statistical tests. $^{37}$

\section{RESULTS}

Baseline demographic and health characteristics of the 12,155 young adults included in the sample are presented in Table 1 by sex and BMI category $(<18.5,18.5-24.9$, or $\geq 25)$. Overall, $33.2 \%$ reported a goal to lose weight, $15.7 \%$ reported a goal to gain weight, and $14.6 \%$ reported a goal to maintain weight. Figure 1 shows unadjusted BMI trajectories using mean BMI at baseline and at each wave of follow-up. Regardless of sex or weight goal, mean BMI for each group increased over time.

\section{Weight Goals and BMI in Men and Women}

Mixed effect models with weight goal as the independent variable and BMI at 7- and 15-year follow-up as the dependent variable, adjusted for age, household income, race/ethnicity, and wave, are presented in Table 2. Among participants with no weight goal at baseline, mean BMI increased by $2.43 \mathrm{~kg} / \mathrm{m}^{2}$ from baseline to 7-year follow-up and $1.17 \mathrm{~kg} / \mathrm{m}^{2}$ from 7-year follow-up to 15-year follow-up. Goals to lose weight were associated with greater BMI increases in men with BMI < 18.5, while goals to maintain weight were associated with greater BMI increases in men with $\mathrm{BMI} \geq 25$. No significant associations were found between any weight goals and BMI change in men with $18.5 \leq \mathrm{BMI}<25$ or in women of all BMI categories.

\section{Weight Control Behaviors and BMI in Men}

Mixed effect models with weight control behaviors as the independent variable and BMI at 7- and 15-year follow-up as the dependent variable, adjusted for age, household income, race/ethnicity, and wave, are presented in Tables 3 and 4 for men and women, respectively. In young men with BMI < 18.5 at baseline, engaging in disordered eating behaviors, particularly fasting/skipping meals, was associated with greater BMI increase over time. There were no significant associations between weight control behaviors and BMI change in young men with $18.5 \leq \mathrm{BMI}<25$ or $\mathrm{BMI} \geq 25$.

\section{Weight Control Behaviors and BMI in Young Women}

In young women with BMI $<18.5$ at baseline, engaging in dieting to lose/maintain weight was associated with greater BMI increase over time. In young women with $18.5 \leq$ BMI $<$ 25 at baseline, dieting and exercise were associated with lower subsequent BMI increase per wave, while engaging in disordered eating behaviors was associated with greater increases in BMI. In particular, of all the disordered eating behaviors examined, engaging in purging behaviors such as diuretic use was associated with the greatest increase in BMI over 
Table 1 Baseline Demographic, BMI, Weight Goal, and Behavior Characteristics of Sample from the National Longitudinal Study of Adolescent to Adult Health (Add Health) by Sex

\begin{tabular}{|c|c|c|c|c|c|c|c|}
\hline & \multirow[t]{2}{*}{ Total } & \multicolumn{3}{|l|}{ Male } & \multicolumn{3}{|l|}{ Female } \\
\hline & & $\begin{array}{l}\text { BMI } \\
<18.5\end{array}$ & $\begin{array}{l}18.5 \leq \mathrm{BMI}< \\
25\end{array}$ & $\mathrm{BMI} \geq 25$ & $\begin{array}{l}\text { BMI } \\
<18.5\end{array}$ & $\begin{array}{l}18.5 \leq \mathrm{BMI}< \\
25\end{array}$ & $\mathrm{BMI} \geq 25$ \\
\hline$N$ & 12,155 & 118 & 2,508 & 2,952 & 278 & 3,183 & 3,116 \\
\hline Demographic characteristics & & \multicolumn{3}{|c|}{ Mean \pm standard error $/ \%$} & \multicolumn{3}{|c|}{ Mean \pm standard error $/ \%$} \\
\hline Age (mean \pm standard error) & $\begin{array}{l}21.80 \\
\pm 0.12\end{array}$ & $\begin{array}{l}21.29 \\
\pm 0.31\end{array}$ & $21.68 \pm 0.13$ & $\begin{array}{l}22.13 \\
\pm 0.12\end{array}$ & $\begin{array}{l}21.49 \\
\pm 0.18\end{array}$ & $21.60 \pm 0.13$ & $\begin{array}{l}21.83 \\
\pm 0.12\end{array}$ \\
\hline \multicolumn{8}{|l|}{ Race/ethnicity } \\
\hline White (non-Hispanic) & $68.19 \%$ & $77.70 \%$ & $68.00 \%$ & $67.05 \%$ & $68.67 \%$ & $73.75 \%$ & $63.44 \%$ \\
\hline $\begin{array}{l}\text { Black/African American } \\
\text { (non-Hispanic) }\end{array}$ & $15.59 \%$ & $8.71 \%$ & $15.62 \%$ & $15.04 \%$ & $13.50 \%$ & $11.59 \%$ & $20.82 \%$ \\
\hline Hispanic/Latino & $11.86 \%$ & $10.67 \%$ & $11.78 \%$ & $12.98 \%$ & $9.49 \%$ & $9.81 \%$ & $13.05 \%$ \\
\hline Asian/Pacific Islander (non-Hispanic) & $3.10 \%$ & $2.93 \%$ & $3.55 \%$ & $3.10 \%$ & $6.81 \%$ & $3.81 \%$ & $1.57 \%$ \\
\hline American Indian/Native American & $0.51 \%$ & $0.00 \%$ & $0.36 \%$ & $0.74 \%$ & $0.00 \%$ & $0.27 \%$ & $0.73 \%$ \\
\hline Other & $0.76 \%$ & $0.00 \%$ & $0.70 \%$ & $1.10 \%$ & $1.53 \%$ & $0.77 \%$ & $0.39 \%$ \\
\hline Household income, thousands of US & 45.99 & 43.10 & $47.01 \pm 1.85$ & 43.50 & 47.80 & $50.85 \pm 2.12$ & 42.77 \\
\hline dollars* & \pm 1.37 & \pm 2.92 & & \pm 1.40 & \pm 3.70 & & \pm 1.29 \\
\hline Body mass index (BMI), $\mathrm{kg} / \mathrm{m}^{2}$ & $\begin{array}{l}26.50 \\
\pm 0.13\end{array}$ & $\begin{array}{l}17.61 \\
\pm 0.07\end{array}$ & $22.19 \pm 0.05$ & $\begin{array}{l}30.60 \\
\pm 0.16\end{array}$ & $\begin{array}{l}17.55 \\
\pm 0.07\end{array}$ & $21.94 \pm 0.04$ & $\begin{array}{l}32.22 \\
\pm 0.18\end{array}$ \\
\hline \multicolumn{8}{|l|}{ Weight goals } \\
\hline Lose weight & $33.16 \%$ & $1.40 \%$ & $5.04 \%$ & $36.99 \%$ & $4.11 \%$ & $29.84 \%$ & $65.32 \%$ \\
\hline Gain weight & $15.71 \%$ & $58.97 \%$ & $38.07 \%$ & $14.42 \%$ & $32.04 \%$ & $6.10 \%$ & $0.49 \%$ \\
\hline Maintain weight & $14.62 \%$ & $2.23 \%$ & $13.63 \%$ & $13.07 \%$ & $14.34 \%$ & $24.81 \%$ & $7.54 \%$ \\
\hline Not trying to change weight & $36.51 \%$ & $37.41 \%$ & $43.26 \%$ & $35.52 \%$ & $49.50 \%$ & $39.25 \%$ & $26.65 \%$ \\
\hline Weight loss/maintenance behaviors ${ }^{\dagger}$ & $47.04 \%$ & $3.63 \%$ & $17.81 \%$ & $49.59 \%$ & $17.95 \%$ & $53.63 \%$ & $72.16 \%$ \\
\hline Dieting & $19.28 \%$ & $0.00 \%$ & $2.94 \%$ & $19.31 \%$ & $7.91 \%$ & $19.70 \%$ & $37.53 \%$ \\
\hline Exercise & $36.46 \%$ & $2.23 \%$ & $15.39 \%$ & $39.38 \%$ & $14.24 \%$ & $42.17 \%$ & $52.64 \%$ \\
\hline Disordered eating behaviors & $11.33 \%$ & $1.40 \%$ & $2.66 \%$ & $10.49 \%$ & $4.87 \%$ & $10.50 \%$ & $23.10 \%$ \\
\hline Fasting/skipping meals & $8.91 \%$ & $1.40 \%$ & $2.16 \%$ & $8.54 \%$ & $4.34 \%$ & $8.32 \%$ & $17.63 \%$ \\
\hline Vomiting & $0.22 \%$ & $0.00 \%$ & $0.07 \%$ & $0.18 \%$ & $0.74 \%$ & $0.31 \%$ & $0.30 \%$ \\
\hline Weight loss pills & $3.41 \%$ & $0.00 \%$ & $0.19 \%$ & $2.59 \%$ & $0.55 \%$ & $3.28 \%$ & $8.20 \%$ \\
\hline Laxatives & $0.29 \%$ & $0.00 \%$ & $0.29 \%$ & $0.12 \%$ & $0.00 \%$ & $0.47 \%$ & $0.35 \%$ \\
\hline Diuretics & $0.34 \%$ & $0.00 \%$ & $0.00 \%$ & $0.32 \%$ & $0.00 \%$ & $0.35 \%$ & $0.75 \%$ \\
\hline
\end{tabular}

All means and percentages are calculated with weighted data to reflect the representative proportion in the target US population

*Household income was reported in Wave I of Add Health (ages 11-18 years). All other baseline data were taken from Wave III of Add Health (ages 18-26 years)

† Sum of individual weight loss/maintenance may be greater than total due to participants' ability to select multiple behaviors

fDisordered eating behaviors were defined as engaging in one of the following weight loss/maintenance behaviors: fasting/skipping meals, vomiting, weight loss pills, laxative use, or diuretic use

time. There were no significant associations between weight control behaviors and BMI change in women with BMI $\geq 25$.

\section{DISCUSSION}

This nationally representative longitudinal study examined the relationship between weight goals, weight control behaviors, and BMI trajectories over 15 years. We found that, among all young adults, BMI trajectories trend upward in unadjusted analyses regardless of weight goal at baseline, but groups differ by baseline BMI. Goals to lose weight in men with BMI $<18.5$ and goals to maintain weight in men with BMI $\geq 25$ were associated with greater BMI increase over time relative to other men in those weight categories but with no weight goal. Engaging in disordered eating behaviors was associated with greater BMI increase in men with BMI < 18.5 and women with $18.5 \leq \mathrm{BMI}<25$. Exercise and dieting were associated with less BMI increase in women with $18.5 \leq$ BMI $<25$, but greater BMI increase in women with BMI $<$ 18.5 , relative to women of the same weight categories. Given the prevalence of these weight goals and behaviors in young adulthood, it is imperative to appropriately screen and counsel this population on long-term weight management.

Previous longitudinal studies have provided convergent evidence of the predictive role of DEBs in adolescence with regard to weight gain. The findings in the current study are consistent with results from Minnesota-based studies examining DEBs and BMI at 15-year follow-up and expand upon studies using Add Health examining only 7-year follow-up. ${ }^{6}$, $14,20,21$ Of note, however, we observe significant relationships regarding DEBs and BMI increase only in young men with $\mathrm{BMI}<18.5$ and young women with $18.5 \leq \mathrm{BMI}<25$ at baseline. Thus, in our sample, those who engaged in DEBs to lose/maintain weight and experienced greater weight gain were already considered underweight/adequate weight at baseline. These findings in participants with lower BMI may reflect individuals who are weight suppressed, and thus more vulnerable to weight increases over time. ${ }^{38}$ In contrast to the DEBs, endorsement of general exercise and dieting to lose/ maintain weight appeared to have the intended effect in young women with $18.5 \leq \mathrm{BMI}<25$. Young women with $18.5 \leq$ 
Men: $\mathrm{BMI}<18.5$

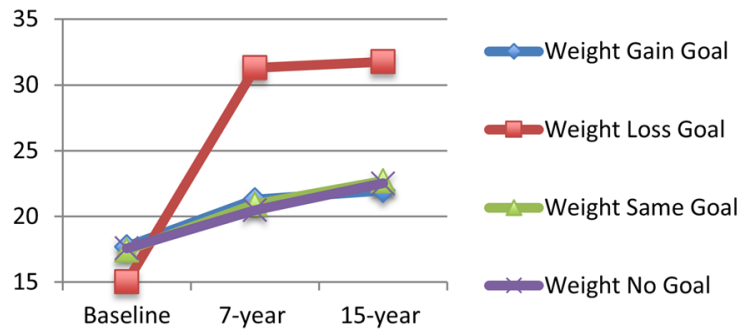

Men: $18.5 \leq \mathrm{BMI}<25$

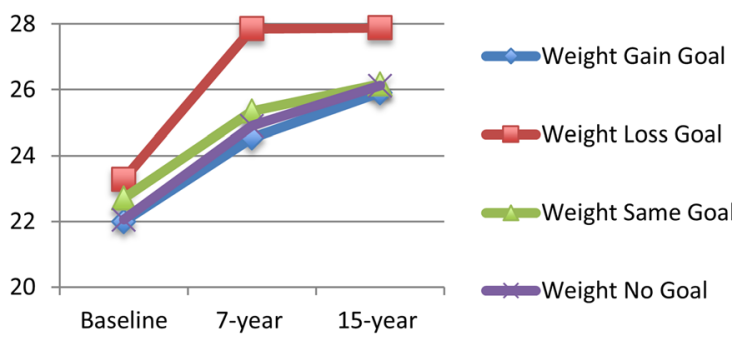

Men: $\mathrm{BMI} \geq 25$
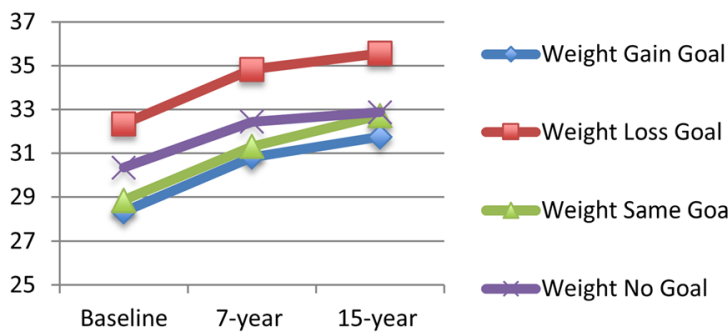

Women: $\mathrm{BMI}<18.5$

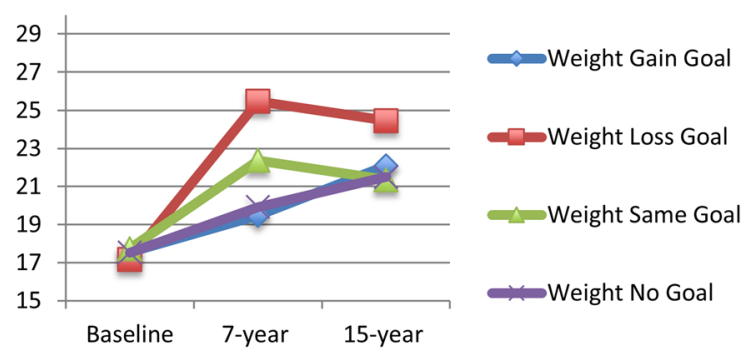

Women: $18.5 \leq \mathrm{BMI}<25$

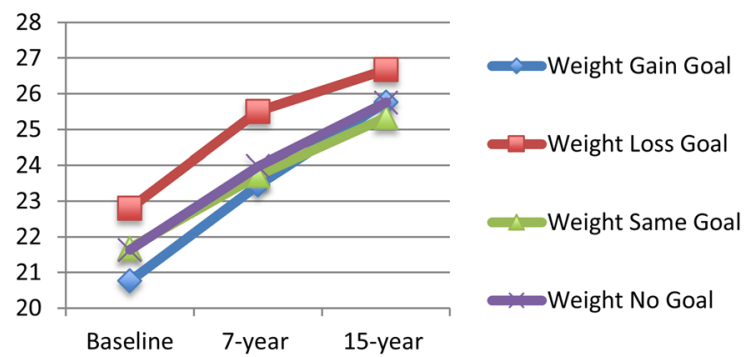

Women: $\mathrm{BMI} \geq 25$

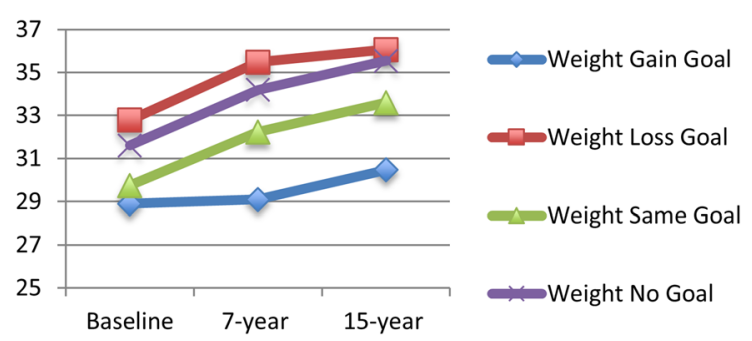

Fig. 1 Unadjusted BMI trajectories of men and women over 15 years of follow-up by $\mathrm{BMI}<18.5,18.5 \leq \mathrm{BMI}<25$, and $\mathrm{BMI} \geq 25$ and by weight goal at baseline.

BMI $<25$ who self-reported dieting or exercise to lose/ maintain weight gained less weight over time, which deviates from previous studies linking dieting to greater weight gain. ${ }^{7}$ However, dieting may be interpreted in different ways. Individuals engaging in more extreme forms of dieting may underreport the severity of their behaviors in the Add Health survey, which may explain why dieting was found to have associations with greater BMI increase in women with BMI < 18.5. Although the prevalence of these weight control behaviors has been shown to be higher in those with higher BMI, it is interesting to note that the greatest effects on change were on those with lower BMI. ${ }^{8}$ It may be that, in the sample, selfreported behaviors were more extreme in those with lower BMI than in those with higher BMI, thus resulting in different findings. Future studies could examine associations between weight goals, weight control behaviors, and changes in BMI category, such as normal weight to overweight.

We found that, of the disordered eating behaviors, purging behaviors such as vomiting, laxative use, and diuretic use had a greater association with BMI increase than restrictive behaviors such as fasting or skipping meals in women with $18.5 \leq$ $\mathrm{BMI}<25$. While restrictive behaviors were associated with greater $\mathrm{BMI}$ increase in men with $\mathrm{BMI}<18.5$, this may be due to the absence of purging behaviors in that subgroup. Though restrictive eating behaviors were much more common in this sample, these findings may reflect differences in how purging and restrictive behaviors impact normal metabolism and physiology. ${ }^{39,}{ }^{40}$ Restrictive eating can further promote bingeeating, and these constant fluctuations may disrupt normal metabolism leading to increases in BMI. ${ }^{39}$ There are a number of theories that may explain why purging behaviors may lead to additional BMI gain. Purging behaviors may eliminate excess calories and lead to decreases in metabolism so that, when an individual discontinues purging, they may have increased weight gain. ${ }^{40}$ Alternatively, purging behaviors may be ineffective at weight loss compared to restrictive behaviors, resulting in greater weight gain overall. ${ }^{41}$ Engaging in purging behaviors, often to compensate for binge-eating, may also reflect a more impulsive personality, which has been shown to have associations with higher BMI. ${ }^{42}$ Together, these findings highlight the varying degrees of long-term consequences associated with different disordered eating behaviors. The relationship between weight control efforts and BMI increase is potentially bidirectional, as those who 
Table 2 Adjusted Change in BMI in US Young Adults with BMI $<18.5,18.5 \leq$ BMI $<25$, or BMI $\geq 25$ by Weight Goal Compared to Those Without a Weight Goal

\begin{tabular}{|c|c|c|c|c|}
\hline \multirow[t]{2}{*}{ Goal } & Male & \multirow[t]{2}{*}{$p$} & Female & \multirow[t]{2}{*}{$p$} \\
\hline & Coefficient* $(95 \%$ CI) & & Coefficient* (95\% CI) & \\
\hline \multicolumn{5}{|l|}{$\mathrm{BMI}<18.5$} \\
\hline No goal & REF & & REF & \\
\hline Lose weight & $5.94(2.58,9.30)$ & 0.001 & $0.98(-0.20,2.16)$ & 0.104 \\
\hline Gain weight & $-0.26(-0.92,0.39)$ & 0.427 & $0.19(-0.27,0.66)$ & 0.414 \\
\hline Maintain weight & $0.84(-0.53,2.21)$ & 0.231 & $0.23(-0.40,0.85)$ & 0.475 \\
\hline \multicolumn{5}{|l|}{$18.5<$ BMI $<25$} \\
\hline No goal & REF & & REF & \\
\hline Lose weight & $0.22(-0.10,0.54)$ & 0.172 & $-0.10(-0.26,0.07)$ & 0.261 \\
\hline Gain weight & $-0.07(-0.22,0.08)$ & 0.386 & $0.25(-0.03,0.53)$ & 0.082 \\
\hline Maintain weight & $-0.16(-0.37,0.04)$ & 0.121 & $-0.23(-0.40,-0.06)$ & 0.009 \\
\hline \multicolumn{5}{|l|}{$\mathrm{BMI}>25$} \\
\hline No goal & REF & & REF & \\
\hline Lose weight & $0.24(0.02,0.45)$ & 0.036 & $0.14(-0.10,0.39)$ & 0.253 \\
\hline Gain weight & $0.29(0.01,0.58)$ & 0.045 & $-0.73(-2.10,0.64)$ & 0.298 \\
\hline Maintain weight & $0.44(0.15,0.72)$ & 0.003 & $0.14(-0.30,0.58)$ & 0.53 \\
\hline
\end{tabular}

Bold indicates statistical significance after Benjamini-Hochberg procedure CI, confidence interval

*Coefficients indicate greater or lower BMI increase per wave of follow-up compared to participants with no weight goal after adjusting for racelethnicity, age, household income, and wave

gain weight are also more likely to engage in healthy and unhealthy attempts to lose weight. ${ }^{11}$ Notably, both weight control behaviors have been shown to peak in young adulthood and there is less engagement with them later in adulthood. $^{3,9,} 31$ Thus, one possible explanation for the greater BMI increase with weight loss goals is the suspension of behaviors in later adulthood as individuals stop trying to lose weight. The greater BMI increase with weight loss/ maintenance efforts may also reflect the all-or-nothing mentality of those who engage in extreme dieting, leading to overcompensation after cessation of weight control behaviors. ${ }^{43}$ Additional studies are needed to highlight specific behaviors that may be detrimental to long-term weight control and their implications for long-term health.

The varying findings in men and women warrant discussion of gender differences in weight control efforts. Though weight maintenance goals were associated with greater BMI increase over time in men with $\mathrm{BMI} \geq 25$, this was not seen in women with $\mathrm{BMI} \geq 25$. This discrepancy may reflect differences in societal body ideals, as men attempting to maintain their weight may do so to maintain a more muscular physique, while women attempting to maintain their weight may do so to achieve a leaner physique. ${ }^{3,4}$ Thus, what it means to have a goal of maintaining weight and the corresponding behaviors taken to achieve this goal may differ between men and women. Similarly, dieting and exercise have been shown to have different presentations among men and women, which may contribute to the contrasting findings we present in the current study. For example, previous studies have found that women are more likely to endorse low-fat and low-carb diets and engage in exercises that tone their bodies compared to men. ${ }^{44}$ Furthermore, due to the gendered nature of weight

Table 3 Adjusted Change in BMI in US Young Men by Weight Control Behaviors and BMI

\begin{tabular}{|c|c|c|c|c|c|c|}
\hline & \multicolumn{2}{|l|}{$\mathrm{BMI}<18.5$} & \multicolumn{2}{|l|}{$18.5 \leq \mathrm{BMI}<25$} & \multicolumn{2}{|l|}{$\mathrm{BMI} \geq 25$} \\
\hline Any weight loss/maintenance behaviors & $1.71(0.45,2.96)$ & 0.008 & $-0.02(-0.19,0.16)$ & 0.858 & $0.18(0.00,0.37)$ & 0.051 \\
\hline Dieting & - & - & $0.13(-0.25,0.51)$ & 0.514 & $-0.01(-0.25,0.22)$ & 0.908 \\
\hline Disordered eating behaviors ${ }^{\dagger}$ & $5.91(2.96,8.86)$ & $<0.001$ & $0.23(-0.20,0.65)$ & 0.300 & $0.21(-0.08,0.50)$ & 0.161 \\
\hline Fasting/skipping meals & $5.91(2.96,8.86)$ & $<0.001$ & $0.18(-0.27,0.64)$ & 0.419 & $0.15(-0.17,0.47)$ & 0.37 \\
\hline Vomiting & - & - & $1.51(-1.72,4.75)$ & 0.359 & $-0.92(-4.02,2.19)$ & 0.563 \\
\hline Diuretics & - & - & - & - & $2.02(-0.61,4.65)$ & 0.133 \\
\hline Purging behaviors & - & - & $-0.23(-2.10,1.64)$ & 0.808 & $0.80(-1.07,2.66)$ & 0.403 \\
\hline
\end{tabular}

Bold indicates statistical significance after Benjamini-Hochberg procedure

Coefficient from mixed effect model. CI, confidence interval

*Coefficients indicate greater or lower BMI increase per wave of follow-up compared to participants not engaging in those behaviors after adjusting for racelethnicity, age, household income, and wave

†Disordered eating behaviors were defined as engaging in one of the following weight loss/maintenance behaviors: fasting/skipping meals, vomiting, weight loss pills, laxatives, or diuretics

$\$$ Purging behaviors were defined as engaging in one of the following weight loss/maintenance behaviors: vomiting, laxatives, or diuretics 
Table 4 Adjusted Change in BMI in US Young Women by Weight Control Behaviors and BMI

\begin{tabular}{|c|c|c|c|c|c|c|}
\hline & \multicolumn{2}{|l|}{ BMI $<18.5$} & \multicolumn{2}{|l|}{$18.5 \leq \mathrm{BMI}<25$} & \multicolumn{2}{|l|}{$\mathrm{BMI} \geq 25$} \\
\hline & Coefficient* (95\% CI) & $p$ & Coefficient* (95\% CI) & $p$ & Coefficient* $(95 \%$ CI $)$ & $p$ \\
\hline Any weight loss/maintenance behaviors & $0.25(-0.31,0.80)$ & 0.008 & $-0.23(-0.36,-0.09)$ & 0.001 & $0.12(-0.12,0.36)$ & 0.316 \\
\hline Exercise & $-0.01(-0.63,0.61)$ & 0.978 & $-0.31(-0.45,-0.17)$ & $<0.001$ & $0.12(-0.10,0.33)$ & 0.277 \\
\hline Dieting & $1.35(0.33,2.37)$ & 0.009 & $-0.24(-0.41,-0.06)$ & 0.009 & $-0.08(-0.30,0.14)$ & 0.473 \\
\hline Disordered eating behaviors ${ }^{\dagger}$ & $0.03(-1.12,1.19)$ & 0.956 & $0.40(0.16,0.63)$ & 0.001 & $0.13(-0.13,0.38)$ & 0.330 \\
\hline Fasting/skipping meals & $0.03(-1.27,1.33)$ & 0.960 & $0.38(0.13,0.64)$ & 0.003 & $0.25(-0.04,0.53)$ & 0.088 \\
\hline Vomiting & $-0.53(-4.00,2.95)$ & 0.765 & $0.36(-1.02,1.54)$ & 0.694 & $0.22(-2.08,2.53)$ & 0.849 \\
\hline Weight loss pills & $0.00(-2.46,2.46)$ & 0.999 & $0.68(0.26,1.10)$ & 0.002 & $-0.43(-0.82,-0.04)$ & 0.030 \\
\hline Laxatives & - & - & $1.00(0.05,1.94)$ & 0.038 & $-1.20(-2.80,0.40)$ & 0.141 \\
\hline Diuretics & - & - & $3.06(1.82,4.31)$ & $<0.001$ & $-0.15(-1.23,0.94)$ & 0.793 \\
\hline Purging behaviors & $-0.53(-4.00,2.95)$ & 0.765 & $1.20(0.50,1.91)$ & 0.001 & $-0.29(-1.16,0.58)$ & 0.51 \\
\hline
\end{tabular}

Bold indicates statistical significance after Benjamini-Hochberg procedure

Coefficient from mixed effect model. CI, confidence interval

*Coefficients indicate greater or lower BMI increase per wave of follow-up compared to participants not engaging in those behaviors after adjusting for racelethnicity, age, household income, and wave

†Disordered eating behaviors were defined as engaging in one of the following weight loss/maintenance behaviors: fasting/skipping meals, vomiting, weight loss pills, laxatives, or diuretics

$\ddagger$ Purging behaviors were defined as engaging in one of the following weight loss/maintenance behaviors: vomiting, laxatives, or diuretics

bias, women may feel the need to engage in more extreme behavioral strategies to control their weight at lower BMIs than men, leading to differences in the quantity or quality of dieting and exercise. In general, a greater percentage of women reported goals to lose weight, while a greater percentage of men reported goals to maintain weight in each BMI category. Because the Add Health study design asked those trying to lose weight and maintain weight the same questions regarding weight control behaviors, it may be that the findings in women reflect a greater engagement in weight loss behaviors. Future studies may seek to investigate how engaging in behaviors to lose weight and engaging in behaviors to maintain weight variably shape BMI trajectories.

We acknowledge several limitations in our study. First, the use of self-reported data in asking about weight goals and behaviors may be subject to reporting bias. Furthermore, the use of BMI as a measure should be noted. While BMI has been traditionally used as a surrogate for body adiposity, it does not distinguish between excess fat, muscle, or bone mass. ${ }^{45}$ Selfreported height or weight was used in subjects missing measures; however, the correlation between self-reported height and weight and clinician-administered measures is 0.98-0.99 in general population samples. ${ }^{46}$ Furthermore, this study did not examine the correlation between BMI and more direct indicators of poor physical health. Thus, we cannot state whether those below or above a BMI of 25 were "healthy" or "unhealthy," respectively. Population data suggests that it is not until a person reaches a BMI of over 35 or 40 that their BMI is associated with significantly poorer health outcomes. ${ }^{11}$ Future studies may consider examining the relationship between disordered eating behaviors and cardiovascular disease risk factors such as hypertension, diabetes, and hyperlipidemia. Lastly, due to the design of Add Health, questions regarding weight loss/maintenance behaviors were restricted to a 7-day time frame, and several of the questions regarding weight goals and behaviors were not asked at all three waves.
Thus, we were unable to examine the persistence and severity of weight goals and behaviors over time.

However, the study has several strengths. It used nationally representative longitudinal data of a large $(n>12,000)$ sample of young adults with three waves of data collection over 15 years. The study is also among the first to examine the associations between weight goals and BMI change over such a lengthy time period.

In conclusion, over $60 \%$ of young adults report a weight goal. Regardless of gender and BMI category, all groups have increased mean BMI over time. Goals to lose weight and goals to maintain weight were associated with greater BMI increase over time in men with $\mathrm{BMI}<18.5$ and $\mathrm{BMI} \geq 25$, respectively. Engaging in disordered eating behaviors was also associated with greater BMI increase in men with BMI $<18.5$ and women with $18.5 \leq \mathrm{BMI}<25$. These findings highlight the sometimes paradoxical relationships between weight goals and behaviors and BMI, underscoring the need to appropriately screen and counsel individuals on effective long-term weight management.

Acknowledgements: This research uses data from Add Health, a program project directed by Kathleen Mullan Harris and designed by J. Richard Udry, Peter S. Bearman, and Kathleen Mullan Harris at the University of North Carolina at Chapel Hill, and funded by grant PO1HD31921 from the Eunice Kennedy Shriver National Institute of Child Health and Human Development, with cooperative funding from 23 other federal agencies and foundations. Information on how to obtain the Add Health data files is available on the Add Health website (https://addhealth.cpc.unc.edu/). No direct support was received from grant PO1-HD31921 for this analysis.

Corresponding Author: Jason M. Nagata, MD, MSc; Division of Adolescent and Young Adult Medicine, Department of Pediatrics, University of California, San Francisco, San Francisco, CA, USA (e-mail: jasonmnagata@gmail.com).

Funding Dr. Nagata was a participant in the Pediatric Scientist Development Program, funded by the American Academy of Pediatrics and the American Pediatric Society, and a recipient of the American Heart Association Career Development Award (CDA34760281). Dr. Murray is supported by NIH K23MH115184. 


\section{Declarations:}

Conflict of Interest: The authors declare that they do not have a conflict of interest.

Open Access This article is licensed under a Creative Commons Attribution 4.0 International License, which permits use, sharing, adaptation, distribution and reproduction in any medium or format, as long as you give appropriate credit to the original author(s) and the source, provide a link to the Creative Commons licence, and indicate if changes were made. The images or other third party material in this article are included in the article's Creative Commons licence, unless indicated otherwise in a credit line to the material. If material is not included in the article's Creative Commons licence and your intended use is not permitted by statutory regulation or exceeds the permitted use, you will need to obtain permission directly from the copyright holder. To view a copy of this licence, visit http://creativecommons. org/licenses/by/4.0/.

\section{REFERENCES}

1. Hales CM, Carroll MD, Fryar CD, Ogden CL. Prevalence of obesity and severe obesity among adults: United States, 2017-2018. NCHS Data Brief 2020;(360): 1-8.

2. U.S. Department of Health and Human Services. Managing Overweight and Obesity in Adults: Systematic Evidence Review from the Obesity Expert Panel. Natl Hear Lung, Blood Inst. Published online 2013. doi:https://doi.org/10.1002/oby.20819

3. Nagata JM, Bibbins-Domingo K, Garber AK, Griffiths S, Vittinghoff E, Murray SB. Boys, Bulk, and Body Ideals: Sex Differences in Weight-Gain Attempts Among Adolescents in the United States. J Adolesc Health 2019;64(4):450-453. https://doi.org/10.1016/j.jadohealth.2018. 09.002 .

4. Tucci S, Peters J. Media influences on body satisfaction in female students. Psicothema. 2008;20(4):521-524.

5. Field AE, Javaras KM, Aneja P, et al. Family, peer, and media predictors of becoming eating disordered. Arch Pediatr Adolesc Med. 2008;162(6):574-579. https://doi.org/10.1001/archpedi. 162.6.574.

6. Neumark-Sztainer D, Wall M, Guo J, Story M, Haines J, Eisenberg M. Obesity, disordered eating, and eating disorders in a longitudinal study of adolescents: how do dieters fare 5 years later?. J Am Diet Assoc 2006;106(4):559-568. https://doi.org/10.1016/j.jada.2006.01. 003.

7. Neumark-Sztainer D, Wall M, Larson NI, Eisenberg ME, Loth $\mathbf{K}$. Dieting and disordered eating behaviors from adolescence to young adulthood: findings from a 10-year longitudinal study. J Am Diet Assoc. 2011;111(7):1004-1011. https://doi.org/10.1016/j.jada.2011.04.012.

8. Nagata JM, Garber AK, Tabler JL, Murray SB, Bibbins-Domingo K. Differential Risk Factors for Unhealthy Weight Control Behaviors by Sex and Weight Status Among U.S. Adolescents. J Adolesc Health 2018;63(3):335-341. https://doi.org/10.1016/j.jadohealth.2018.03.022

9. Nagata JM, Garber AK, Tabler JL, Murray SB, Bibbins-Domingo K. Prevalence and Correlates of Disordered Eating Behaviors Among Young Adults with Overweight or Obesity. J Gen Intern Med 2018;33(8):13371343. https://doi.org/10.1007/s11606-018-4465-Z

10. Darby A, Hay P, Mond J, Guirk F, Buttner P, Kennedy L. The rising prevalence of comorbid obesity and eating disorder behaviors from 1995 to 2005. Int J Eat Disord. 2009;42(2): 104-108. https://doi.org/10.1002/ eat.20601.

11. da Luz FQ, Sainsbury A, Mannan H, Touyz S, Mitchison D, Hay $\mathbf{P}$ Prevalence of obesity and comorbid eating disorder behaviors in South Australia from 1995 to 2015. Int J Obes (Lond). 2017;41(7):1148-1153. https://doi.org/10.1038/ijo.2017.79.

12. McKnight Investigators. Risk factors for the onset of eating disorders in adolescent girls: results of the McKnight longitudinal risk factor study Ipublished correction appears in Am J Psychiatry. 2003 May;160(5):1024]. Am J Psychiatry. 2003;160(2):248-254. https://doi. org/10.1176/ajp.160.2.248.

13. Striegel-Moore RH, Bulik CM. Risk factors for eating disorders. Am Psychol. 2007;62(3):181-198. https://doi.org/10.1037/0003-066X.62.3. 181.

14. Nagata JM, Garber AK, Tabler J, Murray SB, Vittinghoff E, BibbinsDomingo $\mathbf{K}$. Disordered eating behaviors and cardiometabolic risk among young adults with overweight or obesity. Int $\mathrm{J}$ Eat Disord. 2018;51(8):931-941. https://doi.org/10.1002/eat.22927
15. Field AE, Austin SB, Taylor CB, et al. Relation between dieting and weight change among preadolescents and adolescents. Pediatrics. 2003;112(4):900-906. https://doi.org/10.1542/peds.112.4.900.

16. Stice E, Presnell K, Shaw $\mathbf{H}$, Rohde P. Psychological and behavioral risk factors for obesity onset in adolescent girls: a prospective study. J Consult Clin Psychol. 2005;73(2):195-202. https://doi.org/10.1037/0022-006X. 73.2.195.

17. Viner RM, Cole TJ. Who changes body mass between adolescence and adulthood? Factors predicting change in BMI between 16 year and 30 years in the 1970 British Birth Cohort. Int $\mathrm{J}$ Obes (Lond). 2006;30(9):1368-1374. https://doi.org/10.1038/sj.ijo.0803183.

18. Klesges RC, Klem ML, Epkins CC, Klesges LM. A longitudinal evaluation of dietary restraint and its relationship to changes in body weight. Addict Behav. 1991;16(5):363-368. https://doi.org/10.1016/ 0306-4603(91)90030-1.

19. Tiggemann M. Dietary restraint as a predictor of reported weight loss and affect. Psychol Rep. 1994;75(3 Pt 2):1679-1682. https://doi.org/10. 2466/pr0.1994.75.3f.1679.

20. Neumark-Sztainer D, Wall M, Story M, Standish AR. Dieting and unhealthy weight control behaviors during adolescence: associations with 10-year changes in body mass index. J Adolesc Health. 2012;50(1):80-86. https://doi.org/10.1016/j.jadohealth.2011.05.010.

21. Yoon C, Mason SM, Hooper L, Eisenberg ME, Neumark-Sztainer D. Disordered Eating Behaviors and 15-year Trajectories in Body Mass Index: Findings From Project Eating and Activity in Teens and Young Adults (EAT). J Adolesc Health. 2020;66(2):181-188. https://doi.org/10. 1016/j.jadohealth.2019.08.012.

22. Pope HG Jr, Olivardia R, Gruber A, Borowiecki J. Evolving ideals of male body image as seen through action toys. Int $\mathrm{J}$ Eat Disord. 1999;26(1):65-72. https://doi.org/10.1002/(sici) 1098-108x(199907) 26: $1<65$ ::aid-eat8>3.0.co;2-d.

23. Nagata JM, Domingue BW, Darmstadt GL, et al. Gender Norms and Weight Control Behaviors in U.S. Adolescents: a Prospective Cohort Study (1994-2002). J Adolesc Health 2020;66(1):S34-S41. https://doi.org/10. 1016/j.jadohealth.2019.08.020

24. Nagata JM, Braudt DB, Domingue BW, et al. Genetic Risk, Body Mass Index, and Weight Control Behaviors: Unlocking the Triad. Int J Eat Disord 2019;52(7):825-833. https://doi.org/10.1002/eat.23083

25. Pope HG Jr, Khalsa JH, Bhasin S. Body Image Disorders and Abuse of Anabolic-Androgenic Steroids Among Men. JAMA. 2017;317(1):23-24. https://doi.org/10.1001/jama.2016.17441

26. Schreiber GB, Robins M, Striegel-Moore R, Obarzanek E, Morrison JA, Wright DJ. Weight modification efforts reported by black and white preadolescent girls: National Heart, Lung, and Blood Institute Growth and Health Study. Pediatrics. 1996;98(1):63-70.

27. Nagata JM, Ganson KT, Griffiths S, et al. Prevalence and correlates of muscle-enhancing behaviors among adolescents and young adults in the United States [published online ahead of print, 2020 Jun 5]. Int J Adolesc Med Health. 2020. https://doi.org/10.1515/ijamh-20200001.

28. Dean, S., Halpern, C., Harris, K., Liao, D., \& Biemer, P. Sampling and Mixed-Mode Survey Design. 2019. https://doi.org/10.17615/vlvy-a536.

29. Harris KM, Udry JR, Bearman PS. The Add Health Study: Design and Accomplishments. Chapel Hill Carolina Popul Center, Univ North Carolina Chapel Hill. Published online 2013. https://doi.org/10.17615/ C6TW87

30. Tabler J, Utz RL. The influence of adolescent eating disorders or disordered eating behaviors on socioeconomic achievement in early adulthood. Int J Eat Disord. 2015;48(6):622-632. https://doi.org/10. 1002/eat.22395.

31. Stephen EM, Rose JS, Kenney L, Rosselli-Navarra F, Weissman RS Prevalence and correlates of unhealthy weight control behaviors: findings from the national longitudinal study of adolescent health. J Eat Disord. 2014;2:16. Published 2014 Jun 3. https://doi.org/10.1186/2050-29742-16.

32. Neumark-Sztainer D, Story M, Resnick MD, Blum RW. Lessons learned about adolescent nutrition from the Minnesota Adolescent Health Survey. J Am Diet Assoc. 1998;98(12):1449-1456. https://doi.org/10. 1016/S0002-8223(98)00329-0.

33. University of Minnesota. Psychometric testing for EAT 2010 and F-EAT surveys. Univ Minnesota. Published online 2010. http://www.sphresearch.umn.edu/epi/project-eat/

34. Sallis JF, Buono MJ, Roby JJ, Micale FG, Nelson JA. Seven-day recal and other physical activity self-reports in children and adolescents. Med Sci Sports Exerc. 1993;25(1):99-108. https://doi.org/10.1249/ 00005768-199301000-00014. 
35. Gooding HC, Walls CE, Richmond TK. Food insecurity and increased BMI in young adult women. Obesity (Silver Spring). 2012;20(9):18961901. https://doi.org/10.1038/oby.2011.233.

36. Mitchison D, Mond $\mathbf{J}$. Epidemiology of eating disorders, eating disordered behaviour, and body image disturbance in males: a narrative review. J Eat Disord. 2015;3:20. Published 2015 May 23. https://doi. org/10.1186/s40337-015-0058-y.

37. Benjamini Y, Hochberg Y. Controlling the False Discovery Rate: a Practical and Powerful Approach to Multiple Testing. J R Stat Soc Ser B. 1995; 57(1):289-300. https://doi.org/10.1111/j.2517-6161.1995. tb02031.x.

38. Gorrell S, Reilly EE, Schaumberg K, Anderson LM, Donahue JM. Weight and its relation to eating disorder and weight outcomes: a narrative review. Eat Disord. 2019;27(1):52-81. https://doi.org/10. 1080/10640266.2018.1499297.

39. Polivy J, Herman CP. Dieting and binging. A causal analysis. Am Psychol. 1985;40(2):193-201. https://doi.org/10.1037//0003-066x.40. 2.193 .

40. Forney KJ, Buchman-Schmitt JM, Keel PK, Frank GK. The medical complications associated with purging. Int J Eat Disord. 2016;49(3):249259. https://doi.org/10.1002/eat.22504.

41. Anderson L, Shaw JM, McCargar L. Physiological effects of bulimia nervosa on the gastrointestinal tract. Can J Gastroenterol. 1997;11(5):451-459. https://doi.org/10.1155/1997/727645.
42. Liang KY, Meg Tseng MC. Impulsive behaviors in female patients with eating disorders in a university hospital in northern Taiwan. J Formos Med Assoc. 2011;110(9):607-610. https://doi.org/10.1016/j.jfma.2011. 07.010.

43. Haynos AF, Field AE, Wilfley DE, Tanofsky-Kraff M. A novel classification paradigm for understanding the positive and negative outcomes associated with dieting. Int J Eat Disord. 2015;48(4):362-366. https:// doi.org/10.1002/eat.22355.

44. Rolls BJ, Fedoroff IC, Guthrie JF. Gender differences in eating behavior and body weight regulation. Health Psychol. 1991;10(2):133-142. https://doi.org/10.1037//0278-6133.10.2.133.

45. Daniels SR. The use of BMI in the clinical setting. Pediatrics. 2009; 124 Suppl 1:S35-S41. https://doi.org/10.1542/peds.2008-3586F.

46. Pursey K, Burrows TL, Stanwell P, Collins CE. How accurate is webbased self-reported height, weight, and body mass index in young adults?. J Med Internet Res. 2014;16(1):e4. Published 2014 Jan 7. https://doi.org/10.2196/jmir.2909.

Publisher's Note: Springer Nature remains neutral with regard to jurisdictional claims in published maps and institutional affiliations. 